\title{
Microstructure and Mechanical Properties of as-Cast Quasibinary NiTi-Nb Eutectic Alloy
}

\author{
C. Bewerse ${ }^{1}$, L.C. Brinson ${ }^{1,2}$, D.C. Dunand ${ }^{1 *}$ \\ ${ }^{1}$ Department of Materials Science and Engineering, Northwestern University, \\ Evanston, IL, 60208, USA. \\ ${ }^{2}$ Department of Mechanical Engineering, Northwestern University, \\ Evanston, IL, 60208, USA.
}

\section{Corresponding Author (*):}

David C. Dunand

Email: dunand@northwestern.edu

Tel: $847 / 491-5370$

Department of Materials Science and Engineering

Northwestern University

2220 Campus Drive, Cook Hall 2036

Evanston, IL 60208

Keywords: Shape memory alloy, superelastic, eutectic, NiTi, liquid phase sintering

\begin{abstract}
$\mathrm{Ni}_{40} \mathrm{Ti}_{40} \mathrm{Nb}_{20}$ is reported in the literature as a eutectic composition in the quasi-binary $\mathrm{NiTi-Nb}$ system. Eutectic and near-eutectic alloys find applications in various fields, including hydrogen permeation, energy damping, and liquid phase bonding of NiTi structures. In this study, we examine a cast Ni-Ti-Nb alloy with the above eutectic composition. Prealloyed, nearstoichiometric NiTi powders and pure $\mathrm{Nb}$ powders are blended and heated above the eutectic temperature to create a melt with the eutectic composition. After solidification, the ingot shows some elemental segregation at its top and bottom, but a large middle region exists with a
\end{abstract}


homogeneous eutectic structure. The eutectic has average composition of Ti-40.1Ni-19.6Nb at.\% and consists of Nb-rich lamellae (Nb-19Ti-10Ni) dispersed within a NiTi-rich matrix (Ti-41Ni$15 \mathrm{Nb}$ ). Under monotonic compressive deformation, the eutectic alloy yields at $630 \mathrm{MPa}$, and then shows a linear hardening region, where both plastic and superplastic deformation are active, until a stress of $1080 \mathrm{MPa}$ is reached at an applied strain of $14.7 \%$. On unloading, some superelastic strain is recovered. Upon unloading during compressive load-unload cycling, the eutectic alloy exhibits approximately twice as much superelastic recovery as elastic strain recovery, regardless of the maximum cycle strain.

\section{Introduction}

Near equiatomic NiTi alloys are known as shape memory alloys, where a reversible diffusionless phase transformation enables large recovery of strain. In slightly Ni-rich NiTi alloys, the material is stable at room temperatures in the high symmetry B2 austenite phase, and reversibly transforms to the low symmetry monoclinic phase with the application of stress to accommodate deformation (Otsuka \& Ren, 1999). This phenomenon, known as superelasticity, makes the material attractive for a wide variety of applications such as biomedical devices (Morgan, 2004), actuators (Wu \& Schetky, 2000), and energy damping (G. Song, Ma, \& Li, 2006). To control the transformation temperatures and shape memory properties of the material, several ternary additions have been investigated such as Fe, Hf, Pd, or Nb (Humbeeck, 1999; Krishnan, Bewerse, Notardonato, \& Vaidyanathan, 2008; Yang et al., 2013; Yin, Mi, Li, \& Gao, 2012). Alloying with $\mathrm{Nb}$ at low concentrations ( $3.5-5 \mathrm{at} \% \mathrm{Nb}$, with $\mathrm{Ni} / \mathrm{Ti}$ ratios of $\sim 1.09$ ) has been found to increase the yield strength, without significant detriment to the shape memory effect (Ying, Hai-chang, Li-jian, Li, \& Xin-qing, 2011). At increased Nb concentrations, a 
quasi-binary eutectic is reported at a composition of $\mathrm{Ni}_{40} \mathrm{Ti}_{40} \mathrm{Nb}_{20}$ (Piao, Miyazaki, Otsuka, \& Nishida, 1992), which is the focus of this work.

The ternary Ni-Ti-Nb phase diagram has been calculated by several methods, and each of these methods find the same ternary structures with reasonable agreement of the composition and distribution of the phase fields. The eutectic alloy was examined in detail by compositional Electron Probe Micro Analysis (EPMA) by (Piao et al., 1992) who determined a eutectic composition of $\mathrm{Ni}_{40} \mathrm{Ti}_{40} \mathrm{Nb}_{20}$ and an eutectic temperature of $1150^{\circ} \mathrm{C}$. Using data from a wide range of compositions below 30 at. $\% \mathrm{Nb}$, a quasi-binary $\mathrm{NiTi}-\mathrm{Nb}$ phase diagram was created, displayed in Figure 1; it shows that the eutectic should consist of a Ni-45Ti-10Nb at.\% matrix containing $\mathrm{Nb}-13 \mathrm{Ni}-13 \mathrm{Ti}$ at.\% lamellae. The Ti-TiNi-NbNi-Nb region of the ternary phase diagram was investigated with a wide range of $\mathrm{Ni}-\mathrm{Ti}-\mathrm{Nb}$ alloys cast and annealed at $900^{\circ} \mathrm{C}$ (Prima, Tretyachenko, \& Petyukh, 1995). While the eutectic composition determined by Piao et al. was not examined, it was judged that a quasibinary eutectic existed near the Ti-38Ni-26Nb at.\% $\left(\mathrm{Ni}_{38} \mathrm{Ti}_{36} \mathrm{Nb}_{26}\right)$ composition at $1170^{\circ} \mathrm{C}$.

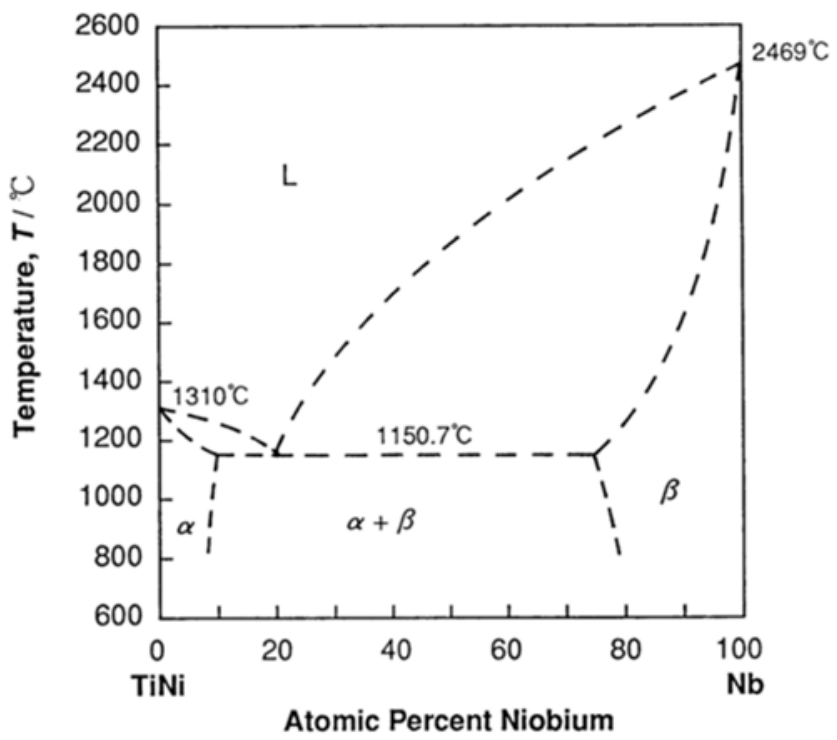

Figure 1: Quasibinary NiTi-Nb phase diagram calculated by Piao et al. (Piao et al., 1992) 
The ternary phase diagram was also calculated using data from a series of diffusion couples between $\mathrm{Ni}-\mathrm{Ti}$ and $\mathrm{Ni}-\mathrm{Nb}$ alloys at $900^{\circ} \mathrm{C}$ and is displayed in Figure $2 \mathrm{~A}$ (Guanjun \& Shiming, 2000). This study did not identify invariant points, but predicted a NiTi $-\beta(\mathrm{bcc}(\mathrm{Nb}, \mathrm{Ti}))$ two-phase region. CALPHAD calculations supported by experimental investigation were also used to create the ternary phase diagram at $700^{\circ} \mathrm{C}, 800^{\circ} \mathrm{C}$, and $900^{\circ} \mathrm{C}$, as well as a liquidus projection, as shown in Figure 2B (Matsumoto, Tokunaga, Ohtani, \& Hasebe, 2005). In this experimental investigation, two series of alloys were investigated with a constant $\mathrm{Ni}$ content of either 28 or 60 at.\% with varying Ti/Nb ratio. While several eutectic points were identified, none were near the $\mathrm{Ni}_{40} \mathrm{Ti}_{40} \mathrm{Nb}_{20}$ composition. Most recently, ternary $\mathrm{Ni}-\mathrm{Ti}-\mathrm{Nb}$ alloys were studied by Grummon et al. (D. S. Grummon, Low, Foltz, \& Shaw, 2007) who used the experimental data reviewed above by (Prima et al., 1995) and (Guanjun \& Shiming, 2000), as well as the $\mathrm{Nb}-\mathrm{Ni}$ and $\mathrm{Nb}$-Ti binary phase diagrams to create a ternary $\mathrm{Ni}-\mathrm{Ti}-\mathrm{Nb}$ ternary phase diagram. They used this diagram to define a quasi-binary $\mathrm{NiTi}-\mathrm{Nb}$ phase diagram, identifying a eutectic point at $\mathrm{Ni}_{37} \mathrm{Ti}_{37} \mathrm{Nb}_{26}$ and $1170^{\circ} \mathrm{C}$, which is a different composition than that reported by Piao et al. $\left(\mathrm{Ni}_{40} \mathrm{Ti}_{40} \mathrm{Nb}_{20}\right.$, which is a composition not covered by the experimental data Grummon et al. uses to construct their quasi-binary phase diagram). In Grummon et al.'s quasibinary phase diagram, the compositions of the NiTi-rich and $\mathrm{Nb}$-rich eutectic constituent phases are $\mathrm{Ni}-43 \mathrm{Ti}-14 \mathrm{Nb}$ and $\mathrm{Nb}-5 \mathrm{Ni}-5 \mathrm{Ti}$, respectively. They thus report lower solubility of both $\mathrm{Nb}$ in the NiTi-rich matrix, and $\mathrm{Ni}$ and $\mathrm{Ti}$ in the Nb-rich lamellae, as compared to Piao et al. 

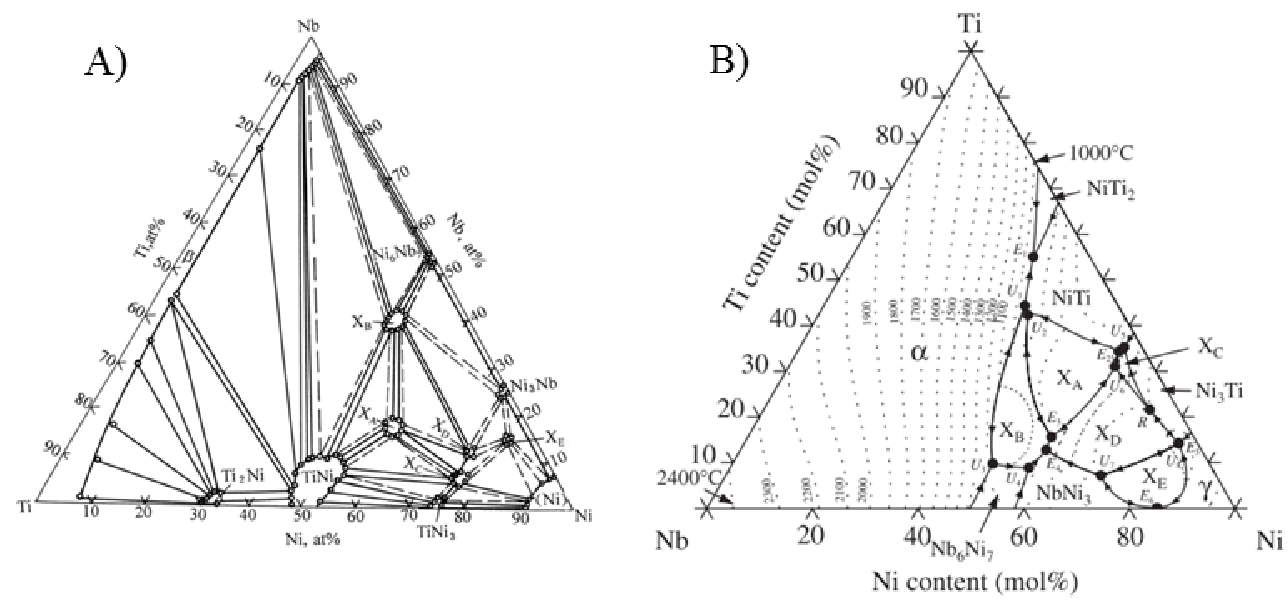

Figure 2: The A) ternary Ni-Ti-Nb phase diagram at $900^{\circ} \mathrm{C}$ as calculated by Guanjun \& Shiming (Guanjun \& Shiming, 2000) and B) the Ni-Ti-Nb liquidus projection (Matsumoto et al., 2005)

The NiTi-Nb eutectic is also of interest due to the high hydrogen permeability of $\mathrm{Nb}$ (Buxbaum \& Marker, 1993). While pure Nb is attractive as a hydrogen permeation membrane due to its low cost and high permeability as compared to other candidates, it is also susceptible to hydrogen embrittlement. However in Nb-NiTi composites, the embrittlement is mitigated while the hydrogen permeation properties are maintained (Ishikawa, Tokui, \& Aoki, 2009). Hydrogen permeation has been found to be directly related to the amount of Nb-rich phase (reported as $\beta(\mathrm{bcc}(\mathrm{Nb}, \mathrm{Ti})))$, whether in the eutectic microstructure or in pro-eutectic NiTi-rich dendrites (reported as NiTi) (Hashi, Ishikawa, Matsuda, \& Aoki, 2004), so alloys with near-eutectic compositions (Matsuda et al., 2009) and at compositions with higher Nb content (Ishikawa, Seki, Kita, Nishida, \& Aoki, 2011) have been closely examined. Regardless of Nb content, the microstructure remains two-phase $\beta(\mathrm{bcc}(\mathrm{Nb}, \mathrm{Ti}))$ and $\mathrm{B} 2-\mathrm{NiTi}$, with the former phase becoming coarser with increased $\mathrm{Nb}$ content (Kishida et al., 2008). The effect of the $\mathrm{Ni} / \mathrm{Ti}$ ratio near the eutectic composition has also been examined (Kato, Ishikawa, \& Aoki, 2008) in a series of $\mathrm{Nb}_{40} \mathrm{Ti}_{30+\mathrm{X}} \mathrm{Ni}_{30-\mathrm{X}}$ specimen. It was found that increased $\mathrm{Ti}$ content resulted in formation of the 
$\mathrm{Ti}_{2} \mathrm{Ni}$ phase, while increased $\mathrm{Ni}$ content yielded the $\mathrm{NbNi}$ phase, in addition to the $\beta(\mathrm{bcc}(\mathrm{Nb}, \mathrm{Ti}))$ and B2-NiTi phases.

The NiTi-Nb eutectic has furthermore been investigated in the context of using the liquid eutectic as a brazing material, or to liquid sinter NiTi porous structures. NiTi is difficult to join with itself or other materials, since methods such as arc-welding or electron beam-welding result in the formation of brittle intermetallic phases at the joint (Akselsen, 2010). However the NiTi$\mathrm{Nb}$ eutectic readily forms strong joints either between two NiTi parts (D. Grummon, Shaw, \& Foltz, 2006), or between $\mathrm{Nb}$ and other materials such as C/SiC (Y. Z. Liu et al., 2011) or Nbcontaining TiAl alloys (X. G. Song, Cao, Liu, \& Feng, 2012). The NiTi-Nb eutectic has also been used for liquid phase sintering, in which small amounts (5.3 wt.\%) of $\mathrm{Nb}$ are blended with NiTi powders to form a limited volume of the eutectic liquid upon heating (Bansiddhi \& Dunand, 2011b). The liquid eutectic has high wettability of the residual unreacted solid NiTi powders, bonding them together upon solidification of the eutectic (Bansiddhi \& Dunand, 2009). This liquid sintering method has been combined with the use of spaceholders such as $\mathrm{NaCl}$, which evaporates during heating, or $\mathrm{Nb}$ wires, which double as a spaceholder and for eutectic formation (Bansiddhi \& Dunand, 2011a).

Tensile properties have been measured for the eutectic alloy, hot rolled with $80 \%$ reduction followed by annealing (Bao, Guo, Xiao, \& Zhao, 2011). The eutectic, which can be assumed to be highly textured by the rolling operation, had a yield strength of $\sigma_{\mathrm{y}}=276 \mathrm{MPa}$, and a tensile strength of $\sigma_{\mathrm{s}}=753 \mathrm{MPa}$ at $51 \%$ elongation. Liu et al. also examined the hot rolled eutectic without annealing, finding a stiffness of $E=78 \mathrm{GPa}$, a yield strength of $\sigma_{\mathrm{y}}=420 \mathrm{MPa}$, and a tensile strength of $\sigma_{\mathrm{s}}=860 \mathrm{MPa}$ (Y. Z. Liu et al., 2011). The tensile properties of the eutectic composition were measured in the martensitic phase at $-80^{\circ} \mathrm{C}$ by Xiao et al. (Xiao et al., 
2007), after hot rolling and subsequent annealing, with a yield strength of $\sigma_{y}=287 \mathrm{MPa}$. In all cases, the eutectic material was found by XRD to have the $\mathrm{B} 2$ crystal structure at room temperature, so superelastic behavior would be expected. However, the as-cast mechanical properties in compression have not been examined, nor have the superelastic properties been characterized.

Here, we examine a cast eutectic alloy, with nominal composition of Ti-38.9Ni-20Nb (at.\% will be used throughout the paper) or $\mathrm{Ni}_{39} \mathrm{Ti}_{41} \mathrm{Nb}_{20}$, created by vacuum melting a blend of prealloyed Ti- 48.6 at\% Ni powders and pure $\mathrm{Nb}$ powders. We examine the microstructure by SEM and use EDS to determine the composition of the phases present in the alloy. The compression properties of the alloy are characterized for monotonic compression to high strains $(15 \%)$, as well as load-unload cycles to investigate the superelastic recovery behavior.

\section{Experimental Methods}

Prealloyed gas atomized NiTi powders with a nominal composition of Ti-48.6 at.\% Ni (Special Metals Corp. Inc) were sieved to a size range of $44-63 \mu \mathrm{m}$. Nb powders, $1-5 \mu \mathrm{m}$ in size (Alfa Aesar), were blended with the NiTi powders to the eutectic composition, NiTi-20 at.\% Nb (Piao et al., 1992), by tumbling for $8 \mathrm{~h}$ in a $40 \mathrm{~mL}$ glass bottle for a nominal cast composition of Ti-38.9Ni-20Nb. The blended powders, contained in an alumina crucible coated with boron nitride, were melted in a high vacuum furnace with a residual pressure of $10^{-6}$ torr, by heating to $1180^{\circ} \mathrm{C}$, above the nominal eutectic temperature, $1150^{\circ} \mathrm{C}$ (Piao et al., 1992). After holding at $1180^{\circ} \mathrm{C}$ for $1 \mathrm{~h}$, the alloy was cooled in vacuum at a rate of $10^{\circ} \mathrm{C} / \mathrm{min}$.

The alloy was prepared for microstructural characterization by grinding with 400, 800, and 1200 grit silicon carbide grinding paper, followed by polishing with $9.0 \mu \mathrm{m}$ diamond 
suspension and $0.05 \mu \mathrm{m}$ colloidal silica suspension. Scanning Electron Microscopy (Hitachi SU8030) and Energy Dispersive X-Ray Spectroscopy (EDS) were used to investigate the alloy microstructure and the composition of its phases. Vickers hardness testing was also performed on the polished surface with a load of $300 \mathrm{~g}$ applied during 5 seconds.

Oxygen and carbon content were measured by ATI Wah Chang Analytical Laboratory. The phase transformation temperatures were determined by Differential Scanning Calorimetry (DSC), also by ATI Wah Chang Analytical Laboratory. For phase transformation temperatures, samples were heated and cooled at a rate of $10^{\circ} \mathrm{C} / \mathrm{min}$ from $-100^{\circ} \mathrm{C}$ to $120^{\circ} \mathrm{C}$. Transformation temperatures austenite start and finish $\left(\mathrm{A}_{\mathrm{S}}, \mathrm{A}_{\mathrm{F}}\right)$ and martensite start and finish $\left(\mathrm{M}_{\mathrm{S}}, \mathrm{M}_{\mathrm{F}}\right)$ were calculated as the interception of the tangents of the peaks and the baseline on the temperature heat flow curves. The eutectic temperature was determined by Differential Thermal Analysis (DTA) at heating at a rate of $10^{\circ} \mathrm{C} / \mathrm{min}$ from $975^{\circ} \mathrm{C}$ to $1275^{\circ} \mathrm{C}$.

Two parallelepipeds were cut by electro discharge machining (EDM) from the homogeneous eutectic microstructure region (Figure 3A and D, region (3)) of the cast eutectic alloy. The surfaces of the specimen were lightly ground with 600 grit silicon carbide grinding paper to remove oxides created by EDM. The compression mechanical properties of these specimens were characterized on a screw-driven load frame (Sintech 20/G), loading and unloading at a rate of $5 \times 10^{-4} \mathrm{~s}^{-1}$. Strain was calculated from the crosshead displacement, corrected for compliance through the direct method in (Kalidindi, Abusafieh, \& El-Danaf, 1997). One specimen, with initial dimensions 5 x 5 × $7.8 \mathrm{~mm}$, was tested under monotonic compression to $15 \%$ strain. A second specimen, with initial dimensions $5 \times 5 \times 8.7 \mathrm{~mm}$, was cyclically tested in load-unload cycles: it was loaded to a predetermined load, and unloaded before loading to the 
next predetermined load. These loads were chosen from the monotonic loading curve to correspond to approximately $0.5,1.0,1.5,2.0,3.0,4.0$ and $7.0 \%$ maximum strain.

\section{Results and Discussion}

\subsection{Macro- and Microstructure}

\subsubsection{Ingot Macrostructure}

The as-cast ingot exhibited elemental segregation and can be separated into four regions, as outlined by dashed lines in Figure 3A. Each of the regions was examined with EDS as detailed below. Separation between the regions was identified by the apparent microstructure in Figure 3A. The extent of each region is estimated by the area fraction in Figure 3A. In the largest middle region (3), representing 61 vol.\% of the ingot, the structure is homogeneously eutectic as displayed in Figure 3D. Two Ni- and Ti- enriched regions (1) and (2) share the top 28 vol.\% of the ingot (Figures 3B and 3C respectively), with an $\mathrm{Nb}$-enriched region (4) at the bottom 11 vol.\% of the ingot (Figure 3E). Due to the density difference between $\mathrm{Nb}\left(8.57 \mathrm{~g} / \mathrm{cm}^{3}\right)$ and NiTi (6.45 g/ $\mathrm{cm}^{3}$ ) (Jackson, Wagner, \& Wasilewski, 1972)), the denser Nb settled towards the bottom of the ingot prior to solidification. A correspondingly $\mathrm{Ni}$ - and Ti- enriched region (2) formed above the eutectic structure, with an additional, highly Ti-enriched, top region (1). 

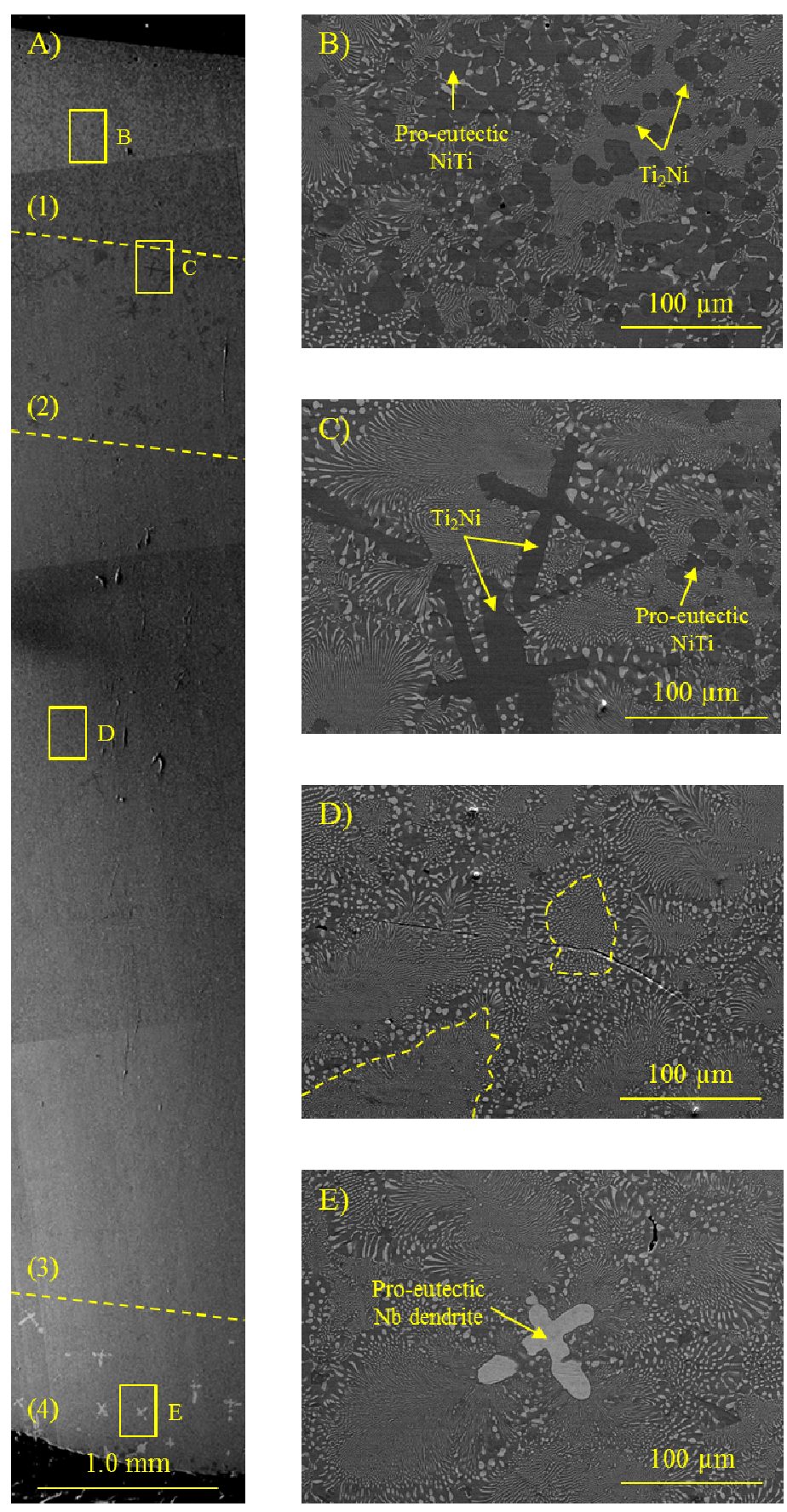

Figure 3: SEM micrographs of cast ingot longitudinal cross-section, showing four distinct regions (1-4) showed at higher magnification in: B) highly Ti-enriched region (1) at the ingot top with pro-eutectic $\mathrm{NiTi}$ and $\mathrm{Ti}_{2} \mathrm{Ni}$ precipitates marked, C) $\mathrm{Ni}$ - and $\mathrm{Ti}$-enriched region with proeutectic NiTi and $\mathrm{Ti}_{2} \mathrm{Ni}$ dendrites marked (2), D) homogeneous eutectic microstructure region (3) 
with several eutectic colonies outlined and $\mathrm{E}$ ) $\mathrm{Nb}$-enriched region at the ingot bottom with proeutectic $\mathrm{Nb}$ dendrites marked (4)

\subsubsection{Eutectic Microstructure}

The phase transformation temperatures as measured by DSC of the eutectic region $\left(\mathrm{M}_{\mathrm{F}}=\right.$ $-191^{\circ} \mathrm{C}, \mathrm{M}_{\mathrm{S}}=-79^{\circ} \mathrm{C}, \mathrm{A}_{\mathrm{S}}=-66^{\circ} \mathrm{C}, \mathrm{A}_{\mathrm{F}}=-28^{\circ} \mathrm{C}$ ) indicate that the eutectic matrix is austenitic at room temperature, despite the alloy being cast with shape-memory NiTi powders which were martensitic at room temperature. Carbon and oxygen contents were measured to be 70 and 530 ppm by weight, respectively. The eutectic microstructure in Figure 3D is homogeneous through the region (3). It is characterized by equiaxed eutectic colonies, 50-100 $\mu \mathrm{m}$ in diameter, several of which are outlined in Figure 3D. The Nb-rich lamellae within the eutectic colonies are finely dispersed. Kishida et al. described the Nb-rich lamellae as rods (Kishida et al., 2008). In Figure 4A, longitudinal cross-sections of the rod-shaped $\mathrm{Nb}$ rich lamellae are observable in the fine microstructure in the lower left of the figure. In the upper right of the figure, the cross-sections of the lamellae are radial, as indicated by their round shape. The lamellae within the fine microstructure are $\sim 0.5 \mu \mathrm{m}$ in diameter. The length of the lamellae is limited by the size of the eutectic colonies, and appears to be an appreciable fraction of the colony size. In the lower left of Figure 4A, elongated lamellae are visible. There is high variation in the length, depending on the angle of the cross section, but the average length in the cross-section is $\sim 30 \mu \mathrm{m}$. Several orientations of the aligned lamellae are visible within the single eutectic colony, indicating multiple solidification nucleation points. 

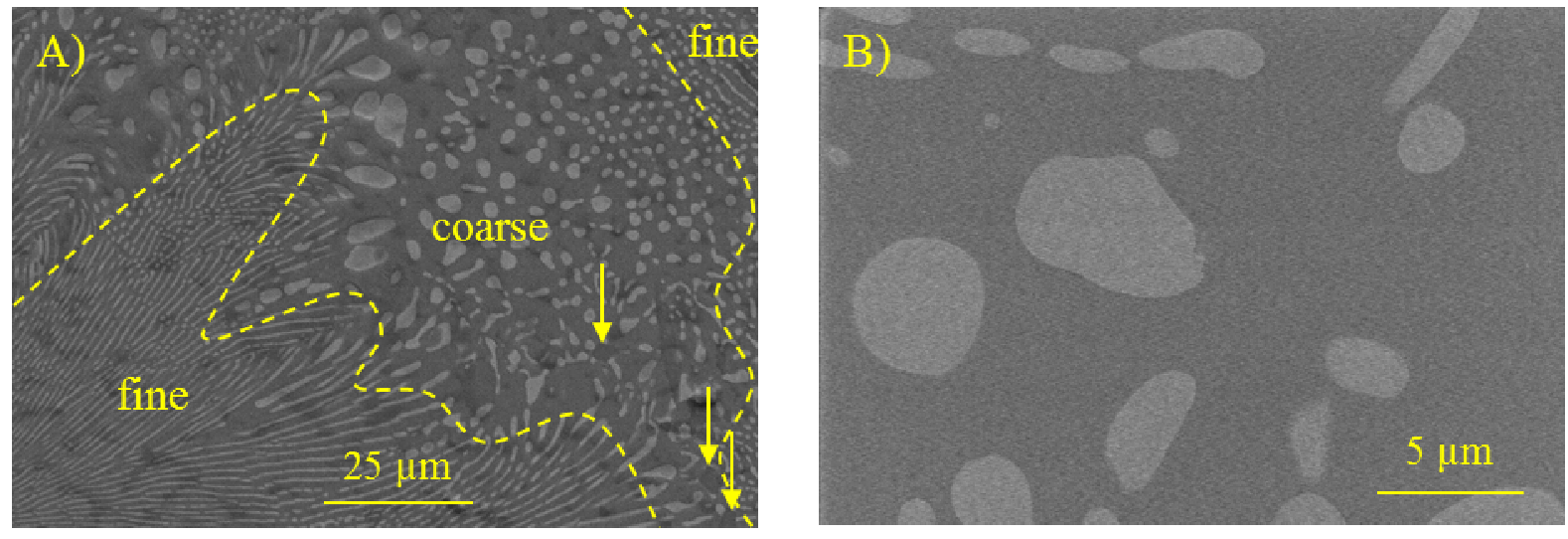

Figure 4: SEM micrographs of the eutectic microstructure in region (3) showing the A) the fine eutectic microstructure (outlined) and coarse interphase microstructure with $\mathrm{Ti}_{2} \mathrm{Ni}$ precipitates indicated with arrows, and B) high magnification of the coarse interphase

A coarser microstructure is found at the boundary between eutectic colonies, hereafter referred to as the interphase. While the boundary has been outlined in Figure 4A, is it not a discrete interface. This interphase has $\mathrm{Nb}$-rich precipitates that are approximately equiaxed with a diameter of $\sim 2 \mu \mathrm{m}$, though several elongated precipitates close to the fine eutectic structure are larger with a major axis of $\sim 9 \mu \mathrm{m}$. Also within the interphase, a few faceted precipitates, with darker phase contrast, are observed, as marked with thin arrows in Figure 4A. These precipitates are also observed in region (1) and (2). Throughout the ingot, we identify them as $\mathrm{Ti}_{2} \mathrm{Ni}$ precipitates with a composition Ti-29.4Ni-16.4Nb $( \pm 0.4(\mathrm{Ti}), 0.5(\mathrm{Ni}), 0.9(\mathrm{Nb})$ at.\%). Unless noted otherwise, all EDS results are measured with a $0.9 \mu \mathrm{m}$ probe size, and are reported from multiple measurements from which the standard deviation is reported as the precision of the measurement. In region (3) the $\mathrm{Ti}_{2} \mathrm{Ni}$ precipitates are small, 3-4 $\mu \mathrm{m}$, and only three of them are visible in Figure 4A. In literature, $\mathrm{Ti}_{2} \mathrm{Ni}$ precipitates were found to form for $\mathrm{Ni} / \mathrm{Ti}$ ratio below unity, regardless of the $\mathrm{Nb}$ content of the alloy (Kato et al., 2008; Piao et al., 1992). Here, our 
nominal cast composition was Ti-enriched with a $\mathrm{Ni} / \mathrm{Ti}$ ratio of 0.95 , and $\mathrm{Ti}_{2} \mathrm{Ni}$ precipitates are observed throughout the ingot.

The average composition of both the fine eutectic microstructure and the interphase, as measured by EDS over areas of $\sim 900-2500 \mu \mathrm{m}^{2}$ (14 and 11 areas respectively) throughout the homogeneous eutectic region (3), is very close to the eutectic composition. In the fine microstructure, the average composition is Ti- $40.1 \mathrm{Ni}-19.8 \mathrm{Nb},( \pm 0.5(\mathrm{Ti}), 0.8(\mathrm{Ni}), 1.1(\mathrm{Nb})$ at.\%) while in the interphase the nominal composition is Ti-38.6Ni-20.9Nb $( \pm 0.5(\mathrm{Ti}), 0.7(\mathrm{Ni}), 0.9$ $(\mathrm{Nb})$ at.\%). These compositions agree with the published eutectic composition Ti-40Ni-20Nb in Figure 1 (Piao et al., 1992). In fact, within all regions of the ingot - (1) and (2) Ti- and Nienriched, (4) $\mathrm{Nb}$-enriched, or (3) homogeneous eutectic microstructure - the average composition of the fine eutectic microstructure is Ti-40.1Ni-19.6Nb $( \pm 0.7(\mathrm{Ti}), 1.0(\mathrm{Ni}), 1.0(\mathrm{Nb})$ at.\%), which is within experimental EDS error ( $\pm \sim 1$ at. \%) of $\mathrm{Ni}_{40} \mathrm{Ti}_{40} \mathrm{Nb}_{20}$ regardless of the nominal composition of the region.

In the coarse interphase microstructure, the composition of the NiTi-rich phase was measured to be Ti-41Ni-14.8Nb $( \pm 0.1(\mathrm{Ti}), 0.5(\mathrm{Ni}), 0.6(\mathrm{Nb})$ at.\%), while the composition of the Nb-rich phase was $\mathrm{Nb}-19.3 \mathrm{Ti}-10 \mathrm{Ni}( \pm 0.1(\mathrm{Ti}), 0.3(\mathrm{Ni}), 0.2(\mathrm{Nb})$ at\%). EDS is not a purely planar technique, and accounting for the depth of the measurement, the volume probed is roughly $15 \mu \mathrm{m}^{3}$. The volume probed depends on the atomic number of the elements examined, with resolution increasing with $\mathrm{Z}$ number, so spatial resolution is somewhat higher for $\mathrm{Nb}$-rich phases than for NiTi-rich phases. Due to the small size and close dispersion of these phases, the error on these compositions is likely higher than \pm 1 at.\%. From the quasi-binary NiTi-Nb phase diagrams constructed by Piao et al. (Figure 1) and Grummon et al., Nb is expected to be in solid solution in NiTi at levels between 10 at.\% (Piao et al., 1992) and 14 at.\% (D. S. Grummon et al., 
2007) at the eutectic temperature, the upper limit of which we find here. Nb is expected to contain between 13 at.\% Ni - 13 at.\% Ti (Piao et al., 1992) and 5 at.\% Ni - 5 at.\% Ti (D. S. Grummon et al., 2007). Here we find the $\mathrm{Ni}$ content in the $\mathrm{Nb}$ rich phase near the upper limit according to the binary phase diagrams, while the Ti content is higher than the expected composition. The $\mathrm{Ni}$ and Ti EDS signals in the $\mathrm{Nb}$ phase may be increased by the surrounding NiTi-rich matrix, though they would be boosted by equivalent amounts. From the Nb-Ni (Chen $\& \mathrm{Du}, 2006)$ and $\mathrm{Nb}-\mathrm{Ti}($ Okamoto, 2002) binary phase diagrams, 4 at.\% Ni dissolves in $\mathrm{Nb}$, while $\mathrm{Ti}$ is fully soluble in $\mathrm{Nb}$ at the NiTi-Nb eutectic temperature, which would result in higher Ti content in the Nb-rich phase.

\subsubsection{Ingot Microstructure}

Comparing the eutectic composition (fine microstructure and coarsened interphase) to the nominal composition of the ingot (Ti-38.9Ni-20.0Nb), it is clear that there must be some elemental segregation within the ingot. This is supported by the Ti enrichment in region (1), segregated from the eutectic. The elemental segregation within the ingot is based on density of the constituent elements. In region (1) at the top of the ingot, the microstructure is Ti-enriched as shown in Figure 3B. In region (1), the eutectic structure is observed, as well as dark gray faceted precipitates, with a composition of Ti-29.3Ni-16.4Nb $( \pm 0.7(\mathrm{Ti}), 0.1(\mathrm{Ni}), 0.9(\mathrm{Nb})$ at.\%), and pro-eutectic NiTi with a composition of Ti-41.9Ni-13.4Nb ( $\pm 0.2(\mathrm{Ti}), 0.6(\mathrm{Ni}), 0.4$ $(\mathrm{Nb})$ at.\%). Each of these structures is indicated in Figure 3B. The faceted Ti-rich precipitates are observed throughout the ingot, as dendrites visible in region (2) and a small volume fraction of precipitates in region (3). These precipitates form when the composition is Ti-enriched from the eutectic composition, and have been identified in literature by $\mathrm{XRD}$ as $\mathrm{Ti}_{2} \mathrm{Ni}$ precipitates 
with $\mathrm{Nb}$ in solid solution (Ishikawa et al., 2011), and elsewhere by EDS as having a near $\mathrm{Ti}_{2} \mathrm{Ni}$ composition (Hashi et al., 2004), though with $\mathrm{Nb}$ content lower than measured in the present investigation. However, in these articles, the alloy was processed at lower temperatures $\left(900^{\circ} \mathrm{C}\right)$ where the solubility of $\mathrm{Nb}$ in $\mathrm{NiTi}$ is lower.

The nominal composition of the eutectic alloy within region (1) remained consistent with the rest of the ingot, at Ti-39.9Ni-19.2Nb $( \pm 1.0(\mathrm{Ti}), 1.8(\mathrm{Ni}) 1.1(\mathrm{Nb})$ at.\%). Calculated by area fraction over Figure 3B, the $\mathrm{Ti}_{2} \mathrm{Ni}$ particles fill $\sim 30$ vol.\% of region (1), while the pro-eutectic NiTi fills $\sim 10$ vol.\%. The remaining volume fraction is composed of the eutectic alloy. Assuming a density of $8.10 \mathrm{~g} / \mathrm{cm}^{3}$ for the $\mathrm{Nb}$ rich lamellae (calculated by averaging the densities of $\mathrm{Nb}\left(8.57 \mathrm{~g} / \mathrm{cm}^{3}\right), \mathrm{Ni}\left(8.90 \mathrm{~g} / \mathrm{cm}^{3}\right)$ and $\mathrm{Ti}\left(4.43 \mathrm{~g} / \mathrm{cm}^{3}\right)$ for a composition of $\left.\mathrm{Nb}-19.3 \mathrm{Ti}-10.0 \mathrm{Ni}\right)$, $6.45 \mathrm{~g} / \mathrm{cm}^{3}$ for the NiTi matrix (Jackson et al., 1972), and $5.77 \mathrm{~g} / \mathrm{cm}^{3}$ for the $\mathrm{Ti}_{2} \mathrm{Ni}$ phase (Duwez \& Taylor, 1950), the nominal composition of region (1) by mass conversion is Ti-37.3Ni-17.9Nb. As compared to the nominal ingot composition, the region is Ti-enriched, with an increase of 3.8 at $\%$ of Ti. The Ni composition is decreased by 1.6 at $\%$, which is within the precision of the EDS measurement, while the $\mathrm{Nb}$ composition is depleted by 2.1 at.\%. The partitioning of Ti to the top of the ingot is encouraging for processing considerations. Even though the nominal composition of the ingot was Ti-enriched as compared to the eutectic composition, a majority of the resultant $\mathrm{Ti}_{2} \mathrm{Ni}$ phase segregated to region (1) rather than remaining interspersed within the eutectic microstructure found in regions (2)-(4).

Region (2) also contains $\mathrm{Ti}_{2} \mathrm{Ni}$ and pro-eutectic $\mathrm{NiTi}$, though the $\mathrm{Ti}_{2} \mathrm{Ni}$ phase is in the form of dendrites rather than faceted precipitates. The compositions of both of these phases agree with the measurements in region (1), as well as the composition of the nominal eutectic microstructure. At the bottom of the ingot, below and adjacent to the homogeneous eutectic 
microstructure, region (4) contains Nb-rich dendrites. These dendrites were measured by EDS to have a composition of $\mathrm{Nb}-16.3 \mathrm{Ti}-6.8 \mathrm{Ni}( \pm 0.3(\mathrm{Ti}), 0.2(\mathrm{Ni}) 0.1(\mathrm{Nb})$ at. \%). The solubility of $\mathrm{Ti}$ in these $\mathrm{Nb}$ rich dendrites is expected from previous observations (Piao et al., 1992) where proeutectic $\mathrm{Nb}$ was observed with a composition of $\mathrm{Nb}-12.4 \mathrm{Ti}-2.6 \mathrm{Ni}$, though these were observed in samples processed at $900^{\circ} \mathrm{C}$. The higher $\mathrm{Ni}$ and $\mathrm{Ti}$ solubility here is likely due to processing at higher temperatures. The presence of these pro-eutectic $\mathrm{Nb}$-rich dendrites indicates $\mathrm{Nb}$ enrichment of region (4) as compared to the homogeneous eutectic microstructure in region (3). This complements the Ni- and Ti-enrichment in regions (1) and (2) above the eutectic microstructure in region (3), indicated by the pro-eutectic $\mathrm{NiTi}$ and $\mathrm{Ni}_{2} \mathrm{Ti}$ dendrite formation in region (2).

\subsection{Mechanical properties}

\subsubsection{Hardness}

The hardness of the eutectic alloy measured on the polished surface is $227 \pm 8 \mathrm{HV}$. The hardness was averaged over 30 indents within the homogeneous eutectic region (3), both over the fine eutectic microstructure, the interphase, and a combination of the two. The indents ranged $\sim 45 \mu \mathrm{m}$ across, spanning the majority of the eutectic colony size, such that hardness is a measurement of the eutectic two-phase mixture, rather than of the lamellae or matrix constituents. Neither pile-up nor sink-in effects were evident with the indents, which would indicate brittle or very ductile qualities respectively (Choi, Lee, Lee, \& Kwon, 2003).

Hardness of the eutectic has also been measured by (Matsuda et al., 2009) for a range of annealed melt-spun eutectic ribbons. A wide range of hardness was found, but the most similar to this study here were a set of ductile samples with a Vickers hardness between 244 and $261 \mathrm{HV}$. 
Another study examined the effect of annealing on the hardness of a series of cold rolled NiTi$\mathrm{Nb}$ alloys (Ishikawa et al., 2009) covering much of the ternary phase diagram between 30 and 60 at.\% Ni, from 10 to 80 at.\% $\mathrm{Nb}$ and from 10 to 60 at.\% Ti. The Vickers hardness was measured for several of the compositions as a function of annealing temperatures, the closest of which to the eutectic composition was $\mathrm{Nb}-30 \mathrm{Ti}-30 \mathrm{Ni}$. The as-cast hardness of this composition was 255 HV (measured to compare to rolled samples), which also compares well to our measurements here. However primary $\mathrm{Nb}$ would be expected at this composition, which may explain the slight increase of hardness as compared to our pure eutectic microstructure.

The hardness of bulk NiTi will vary with the composition and heat treatment. However in a study looking at the hardness of NiTi over a variety of compositions, shape memory NiTi (martensite at room temperature) was found to have a hardness of $234 \mathrm{HV}$, while superelastic NiTi (austenite at room temperature) had a lower hardness of 186HV (Arciniegas, Casals, Manero, Peña, \& Gil, 2008). The as-cast eutectic material is austenite a room temperature, but has a higher hardness than bulk austenite NiTi. As with the inclusion of primary $\mathrm{Nb}$ above, the presence of $\mathrm{Nb}$ in the eutectic matrix increases the hardness with respect to bulk NiTi.

\subsubsection{Compressive properties}

\section{a. Monotonic Deformation}

Figure 5 shows the stress-strain curve for compression of the eutectic material up to $14.7 \%$ strain, performed monotonically, except for a load-unload loop at $4.0 \%$ strain. The initial loading is non-linear, increasing in slope until $200 \mathrm{MPa}$; at this stress, the stiffness is $46 \mathrm{GPa}$, measured over a $40 \mathrm{MPa}$ stress range centered about the inflection point at $200 \mathrm{MPa}$ between concavity and convexity of the loading curve. The concavity is likely due to convolution 
between deformation of the $\mathrm{Nb}$ precipitates and the NiTi matrix, discussed further below. The convex non-linear loading shape past the inflection point is characteristic of the superelastic effect (Brinson, Schmidt, \& Lammering, 2003), where upon loading B2-NiTi austenite phase is starting to transform to martensite leading to the softening response. This is likely convoluted with plastic yielding in the $\mathrm{Nb}$ phase. The yield strength is $630 \mathrm{MPa}$, measured at the intersection of the stiffness slope above $200 \mathrm{MPa}$ and the slope of the plastically yielding plateau. The specimen continued to superelastically and plastically deform until $14.7 \%$ strain where the stress reached $1080 \mathrm{MPa}$ showing a near-linear hardening. Upon subsequent unloading, the alloy shows linear elastic behavior at first, though the unloading slope gradually decreases as the load drops, which is characteristic of the superelastic effect. During superelastic unloading, the martensite reverts to austenite and recovers the accommodated strain, duplicating the non-linear curve shape observed during loading. After full unloading, $12.9 \%$ residual plastic strain remained. The strain of $1.8 \%$ recovered upon unloading is a mixture of elastic strain $(0.6 \%$ determined by extrapolating the elastic curve to zero stress) and superelastic strain $(1.2 \%)$. 


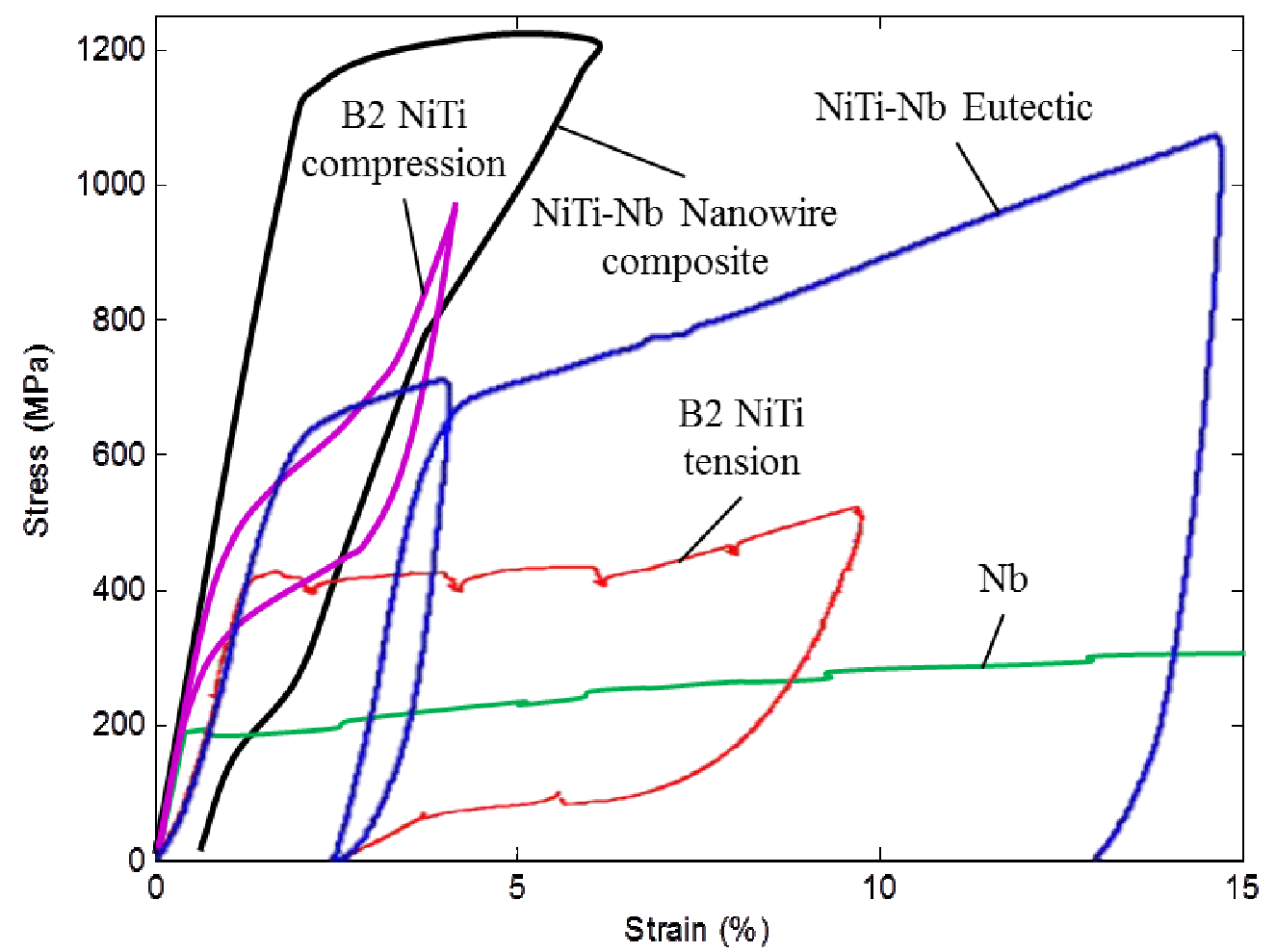

Figure 5: Stress strain curve NiTi-Nb eutectic measured here in compression, compared with tension stress-strain curves for B2 NiTi (Brinson et al., 2003), commercial Nb (Nemat-Nasser \& Guo, 2000), and NiTi-Nb nanowire composite (Z. Liu, Cui, et al., 2014), and a compression stress-strain curve for B2 NiTi (Vaidyanathan, Bourke, \& Dunand, 1999)

Also in Figure 5 are the stress-strain curves for an annealed $\mathrm{Nb}$ rod (Nemat-Nasser \& Guo, 2000), an annealed rolled superelastic NiTi plate in tension (Brinson et al., 2003) and superelastic NiTi hot isostatically pressed from prealloyed powders in compression (Vaidyanathan et al., 1999), and highly textured NiTi-Nb eutectic nanowires (Z. Liu, Cui, et al., 2014). The Nb stress-strain curve shows a sharp plastic yield stress at $200 \mathrm{MPa}$, after which it plastically deforms with a low hardening rate. The NiTi stress-strain curves show high tension/compression asymmetry. In tension, the superelastic yield plateau (at 400 MPa) is 
relatively flat, then hardens plastically past $6 \%$ strain when the superelastic transformation is exhausted, and finally unloads with residual plastic strain. However in compression, the superelastic yield plateau is steeper, initiating at a higher stress near $\sim 500 \mathrm{MPa}$. The superelastic transformation is exhausted at a lower strain (2\%), after which the oriented martensite deforms elastically until the end of the test at $1000 \mathrm{MPa}$, and recovers all strain upon unloading.

Our as-cast NiTi-Nb eutectic composite deforms as a convolution of these behaviors. Though the as-cast eutectic does not have a distinct superelastic plateau, as the pure NiTi B2 materials do, there is still a minor amount of superelastic recovery upon unloading. The yield strength is higher than those of pure $\mathrm{Nb}$ or pure $\mathrm{NiTi}$ in tension, as expected from the strengthening effect of the submicron $\mathrm{Nb}$ precipitates within the NiTi matrix. However, it is the lower than pure NiTi in compression, which is not plastic by even $1000 \mathrm{MPa}$. This discrepancy is discussed later. Additionally, the composition of the present as-cast eutectic NiTi matrix is quite different (e.g. via its $\mathrm{Nb}$ content) from the pure $\mathrm{NiTi}$ in compression.

\section{b. Cyclic Deformation}

Though, in the present as-cast eutectic alloy, minor amounts of superelasticity are clearly exhibited in the monotonic loading curve in the non-linear loading and unloading slopes (though superelastic deformation is likely present at all stages of the stress-strain curve), load-unload cycles were also performed to investigate the mechanical properties with accumulated plastic strain. The seven cycles are plotted in Figure 6, along with the monotonic curve plotted with a black dashed line. The curves have been plotted along the strain axis such that subsequent cycles begin at the unloaded strain of the previous cycle, and that the accumulated residual strain is directly visible on the $\mathrm{X}$-axis. 
These load-unload cycles fit within the envelope given by the monolithic curve well, with the maximum stress in each cycle aligning with the monolithic stress when the accumulated plastic strain is added to the strain of each cycle. The yield strength remains nearly constant at $630 \mathrm{MPa}$ for all cycles, though it becomes more difficult to identify as yielding becomes more diffuse with higher accumulated residual plastic strains. The plastic yielding, work-hardening plateau for each cycle also matches the monolithic curve well. The concave non-linear behavior upon both loading and unloading becomes more pronounced with increased cycling. This low strain behavior upon loading is a convolution of the linear elastic range within $\mathrm{Nb}$ precipitates with low strain superelastic transformation in the NiTi matrix. While the majority of the NiTi matrix does not transform until the yield plateau, regions with internal stresses due to the NiTi matrix- $\mathrm{Nb}$ precipitate strain mismatch (discussed in more depth below) transform from austenite to martensite at lower applied strains. As the $\mathrm{Nb}$ precipitates are plastically hardened, the behavior extends to higher stresses, increasing the extent of the concave behavior. After the inflection point, $\mathrm{Nb}$ precipitates have plastically yielded and the stress-strain behavior is driven by the NiTi matrix. The remaining majority of the NiTi matrix then transforms from austenite to martensite at the yield plateau, at $630 \mathrm{MPa}$. With cycling to higher strains, higher volume fractions of NiTi transform to the martensitic phase, and revert upon unloading. This reverse austenite to martensite transformation produces the higher level of concavity in the unloading curves. 


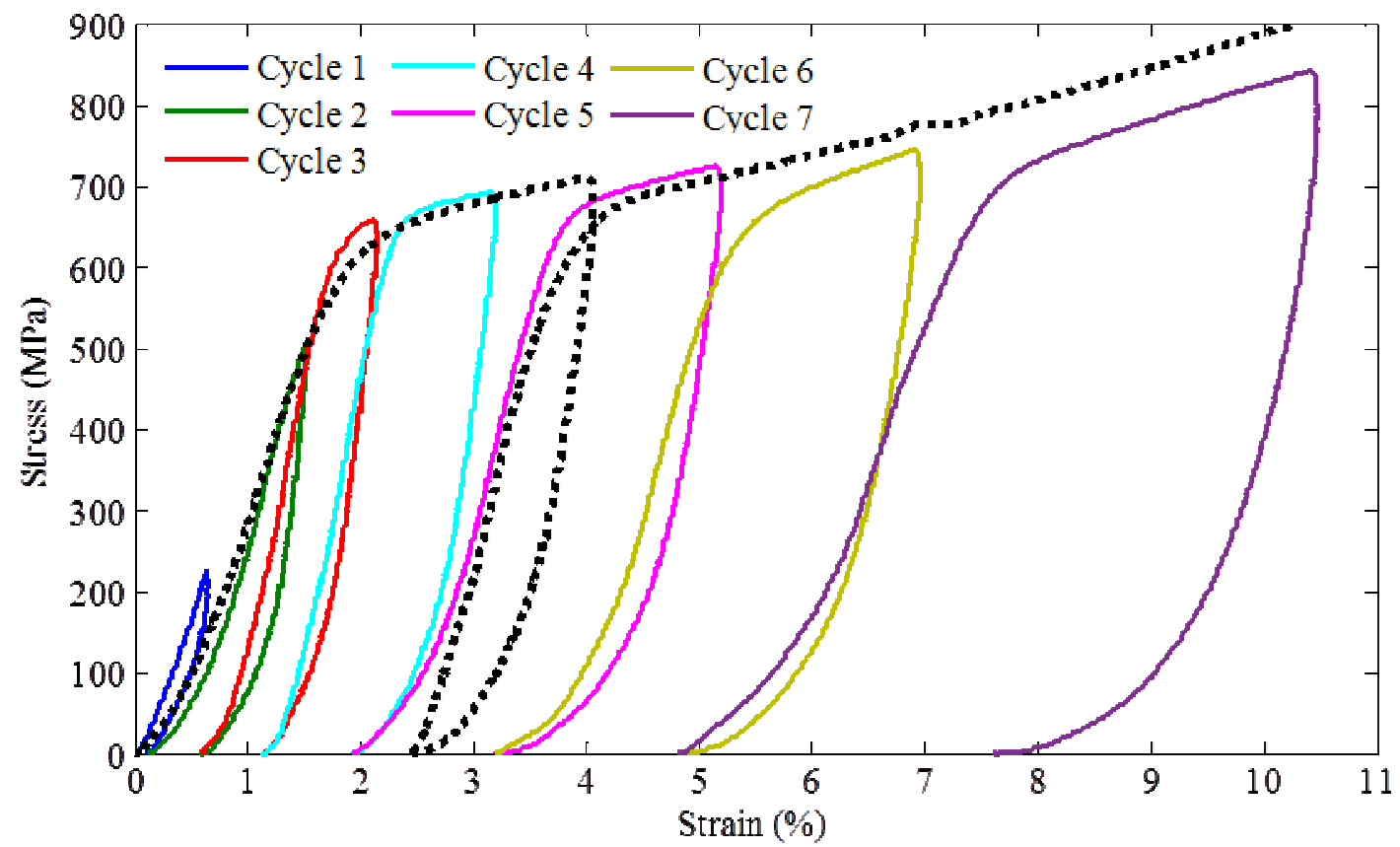

Figure 6: The eight stress-strain curves for compressive load-unload cycles are plotted with accumulated residual plastic strain in thin lines. The monotonic curve is plotted in a dashed line for comparison.

To quantify the load-unloading cycles, we measure the individual strain components of each of the load-unload cycles, as done in (Neurohr \& Dunand, 2011a, 2011b). For each cycle, the strain was divided into three components: the elastic recovery strain $\left(\Delta \varepsilon_{\mathrm{el}}\right)$, the superelastic recovery strain $\left(\Delta \varepsilon_{\mathrm{se}}\right)$, and the residual plastic strain $\left(\Delta \varepsilon_{\mathrm{pl}}\right)$. The sum of these three strains is the maximum strain of each cycle $(\Delta \varepsilon)$. The accumulated residual plastic strain, $\Delta \varepsilon_{\text {res }}$, is the summation of residual plastic strain from the previous cycles, i.e., the total residual plastic strain at the beginning of the cycle. The total applied strain, plotted against each of the individual strain components in Figure 6, is the sum of the accumulated residual strain with the maximum strain for each cycle, or: 


$$
\varepsilon_{\text {tot }}=\Delta \varepsilon+\Delta \varepsilon_{\text {res }}=\Delta \varepsilon_{e l}+\Delta \varepsilon_{s e}+\Delta \varepsilon_{p l}+\Delta \varepsilon_{r e s}
$$

To measure the elastic recovery strain, the linear portion of the unloading curve, beginning 100 MPa below the maximum stress to remove machine effects, was extended to zero stress. The difference between this strain and the maximum applied strain of the cycle is the elastic recovery strain. The remaining unloading strain recovery, measured from the intersection point to the final, measured unloaded strain, is the superelastic recovery strain. The residual plastic strain is then the unloaded strain.

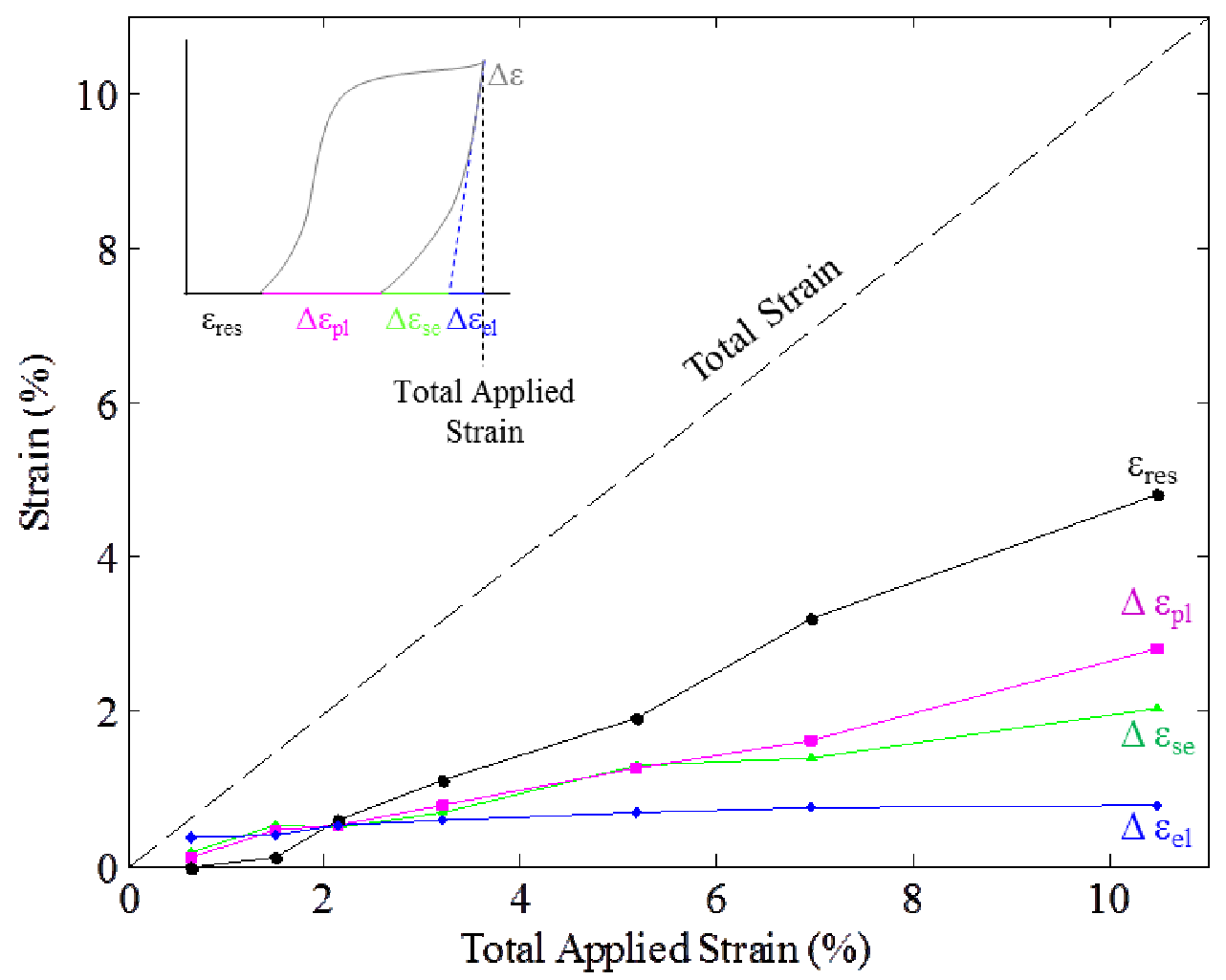

Figure 7: The incremental strain components (elastic recovery strain $\Delta \varepsilon_{\mathrm{el}}$, superelastic recovery strain $\Delta \varepsilon_{\mathrm{se}}$, residual plastic strain $\Delta \varepsilon_{\mathrm{pl}}$, and the accumulated residual plastic strain $\left.\Delta \varepsilon_{\mathrm{res}}\right)$ plotted against the total applied strain $\varepsilon_{\text {tot }}$. Error bars are within the size of the markers. A schematic of the individual strain components on a stress-strain plot is inset. 
The unloading, recoverable strain components, $\varepsilon_{\mathrm{el}}$ and $\varepsilon_{\mathrm{se}}$ dominate the maximum strain for the first four cycles, below $\varepsilon_{\text {tot }}=2.0 \%$, though even in the first cycle there is a small amount of residual plastic strain $\left(\Delta \varepsilon_{\mathrm{pl}}=0.1 \%\right)$. Starting in the third cycle, in which the maximum cycle stress is just above the yield stress, $\left(\varepsilon_{\mathrm{tot}}=2.1 \%, \sigma_{\max }=660 \mathrm{MPa}\right)$, the residual plastic strain increases linearly with cycling to a maximum strain $\Delta \varepsilon_{\mathrm{pl}}=2.8 \%$ in the last cycle $\left(\varepsilon_{\mathrm{tot}}=10.5 \%\right)$. The superelastic recovery strain $\Delta \varepsilon_{\mathrm{se}}$ increases at a slightly lower rate, such that in the last cycle the magnitude of the superelastic recovery strain is $\varepsilon_{\mathrm{se}}=2.0 \%$. The superelastic recovery strain increases with increased cycling as higher volume fractions of the NiTi matrix orient to martensite at the higher strain levels, despite the plasticity in other regions. The elastic recovery strain doubles over the length of the test, from $\Delta \varepsilon_{\mathrm{el}}=0.4 \%$ strain in the first cycle to $\Delta \varepsilon_{\mathrm{el}}=0.8 \%$ strain in the last cycle, though the magnitude of the elastic recovery strain is less than the superelastic and residual plastic strain components starting at the fourth cycle.

Table 1: Mechanical Properties measured on eutectic NiTi, as well as literature values for B2 $\mathrm{NiTi}$ in tension and in compression, and pure niobium for comparison. IWQ and OQ represent ice water quench and oil quench, respectively.

\begin{tabular}{|c|c|c|c|c|}
\hline & \multicolumn{3}{|c|}{ B2 NiTi } & \multirow[b]{2}{*}{ Niobium $^{\underline{3}}$} \\
\hline & Eutectic NiTi & Tension $^{1}$ & Compression $^{\underline{2}}$ & \\
\hline Stiffness (GPa) & 46 & 45 & 50 & 105 \\
\hline Yield Strength (MPa) & 630 & 400 & 480 & 200 \\
\hline Composition (at\%) & Ti-38.9Ni-20Nb & $\mathrm{Ni}-49.5 \mathrm{Ti}$ & $\mathrm{Ni}-49.0 \mathrm{Ti}$ & 99.9\% Purity Nb \\
\hline Heat Treatment & $\begin{array}{c}1180^{\circ} \mathrm{C} / 1 \mathrm{hr}, \\
\text { cooled at } 10^{\circ} \mathrm{C} / \mathrm{min}\end{array}$ & $\begin{array}{c}750^{\circ} \mathrm{C} / 1 \mathrm{hr}, \text { IWQ, } \\
525^{\circ} \mathrm{C} / 8 \mathrm{~min}, \text { IWQ }\end{array}$ & $\begin{array}{l}1000^{\circ} \mathrm{C} / 1 \mathrm{hr}, \mathrm{OQ} \\
400^{\circ} \mathrm{C} / 1 \mathrm{hr}, \text { IWQ }\end{array}$ & $\begin{array}{c}1020^{\circ} \mathrm{C} / 1 \mathrm{hr}, \text { cool } \\
\text { under vacuum }\end{array}$ \\
\hline
\end{tabular}


Data is from (Brinson et al., 2003) ${ }^{1}$, (Vaidyanathan et al., 1999) ${ }^{2}$, and (Nemat-Nasser \& Guo, $2000)^{3}$. Yield strength for the B2 NiTi materials refers to the onset of the stress induced transformation, while it refers to the onset of plasticity for the eutectic NiTi and niobium.

The mechanical properties of pure $\mathrm{Nb}$ (Emsley, 1999; Nemat-Nasser \& Guo, 2000) and B2-NiTi in both tension (Brinson et al., 2003) and compression (Vaidyanathan et al., 1999) are very different from those measured here for the eutectic alloy, as listed in Table 1. The eutectic alloy is a composite consisting of submicron Nb-rich lamellae within a B2-NiTi-rich matrix, so its mechanical properties are a convolution of those of the two phases, with both precipitation strengthening (blocking dislocations) and composite strengthening (load transfer from matrix to particles, Vaidyanathan, Bourke, \& Dunand, 1999) expected. The microscopic stress and strain coupling between NiTi and Nb-nanowires in tension was recently studied by Liu et al. through TEM (Z. Liu, Cui, et al., 2014) and X-ray diffraction (Z. Liu, Liu, et al., 2014). While the microstructure in this study is highly textured, as contrasted to our as-cast microstructure, the same NiTi-Nb eutectic composition was used in this study resulting in the same constituent phases. Therefore we use this study here to gain insight on the deformation mechanisms active within, and the load transfer between, each phase in our NiTi-Nb eutectic material.

An ingot of the NiTi-Nb eutectic with a nominal composition of Ti-41Ni-20Nb was prepared by vacuum induction melting, hot drawn into $1.0 \mathrm{~mm}$ diameter wires, annealed, and then cold drawn without annealing to a diameter of $0.55 \mathrm{~mm}$. The resulting wires contained highly aligned, 30-50 $\mathrm{nm}$ diameter $\mathrm{Nb}$ nanowires with a high aspect ratio in a B2-NiTi matrix. The NiTi-Nb nanowire composite deformed with linear elastic behavior, followed by nearly flat plateau at $1210 \mathrm{MPa}$ up to $6 \%$ strain. Upon unloading, only $0.5 \%$ residual plastic strain 
remained, with 5.5\% strain recovered through elastic and superelastic strain recovery.

Subsequent loading cycles to $8 \%$ and $16 \%$ strain exhibited a more diffuse transition between the linear elastic region and the yield plateau, but still with very high recovery of strain upon unloading. Liu et al. theorized in (Z. Liu, Cui, et al., 2014) and then experimentally verified in (Z. Liu, Liu, et al., 2014) that internal stresses develop during cycling due to the mismatch between the elastic recovery of the $\mathrm{Nb}$ nanowire and the superelastic recovery of the NiTi matrix. This has also previously been shown through $\mathrm{x}$-ray diffraction in a NiTi-Cu shell-core wire (Hao et al., 2013). During loading, the $\mathrm{Nb}$ nanowires deform, first elastically and then plastically, to match the superelastic strain of the NiTi matrix. Upon unloading, the $\mathrm{Nb}$ nanowires are only able to recover their elastic deformation, which impedes the superelastic recovery of the NiTi matrix. Furthermore, the superelastic recovery of the NiTi matrix was found to induce compressive strains on the $\mathrm{Nb}$ wires upon unloading. It was determined that only a small volume of the NiTi matrix adjacent to the $\mathrm{Nb}$ nanowires experienced these internal mismatch stresses, though this effect was sufficient to influence the macroscopic stress-strain curve.

The same mechanisms are likely active in our as-cast eutectic material. We can use the strain components to identify the dominant deformation mechanisms during cyclic loading. While it is clear that deformation mechanisms are not active without interaction with each other, it is useful to discuss what mechanisms may be dominant at different strain levels during compressive loading. At low applied strains, both NiTi matrix and Nb lamellae deform elastically. The composite stiffness is then between that of $\mathrm{NiTi}$ and $\mathrm{Nb}$, and can be predicted using composite theories, taking into account $\mathrm{Nb}$ lamellae volume fraction, aspect ratio and orientation. However, the phase transformation responsible for the superelastic effect will also initiate at low strains within the NiTi matrix due to stress concentrations between matrix and 
lamellae, and among matrix grains, and the measured apparent stiffness in the linear portion of the stress-strain curve will be lower than the Young's modulus predicted from elastic theory.

With increased applied strain, the NiTi matrix deforms primarily superelastically by the stress-induced transformation, and its strain is locally matched first by elastic and then by plastic deformation of the $\mathrm{Nb}$ lamellae. The residual plastic strain component of the eutectic specimen increases sharply after $2 \%$ total applied strain (Figure 7), which coincides with the macroscopic yield strength of the specimen, and is probably driven by the large-scale yielding of the $\mathrm{Nb}$ lamellae phase. While some grains within the NiTi matrix are likely also plastically deforming, the deformation within the NiTi matrix is probably dominated by superelastic deformation at lower strains. With continued cycling to higher cycle strains, there is an increase of both the residual plastic strain - presumably dominant in the $\mathrm{Nb}$ lamellae though also present in the NiTi matrix - and the superelastic recovery strain from the NiTi matrix. However in the above study (Z. Liu, Cui, et al., 2014), their composite structure was heavily cold-drawn, so that both the NiTi matrix and the $\mathrm{Nb}$ nanowires were cold worked and textured, which resulted in a much higher yield stress (1220 MPa as compared to our $630 \mathrm{MPa}$ ) and different strain hardening behavior. Their fully aligned, plastically deformed $\mathrm{Nb}$ fibers also have different load transfer behavior than our randomly aligned, as cast $\mathrm{Nb}$ lamellae colonies, as well as differences in the interface between $\mathrm{NiTi}$ and $\mathrm{Nb}$ due to the plastic deformation. Finally, mechanical characterization in their study was done in tension, which, due to the tension-compression asymmetry in shape memory alloys (Y. Liu, Xie, Van Humbeeck, \& Delaey, 1998), yields different results than our current compressive study.

\section{c. Engineering Applications}


The NiTi-Nb eutectic, with its combination of high compressive strength and good ductility, is attractive as bond material (for NiTi with itself or with other materials); the mechanical properties measured here can be used to improve design efficiency and failure prediction of the bonded structures. The compositional analysis done here can also be useful in guiding processing refinement in other systems using bulk NiTi-Nb eutectic composites, such as for hydrogen permeation or energy damping applications. In addition, the present study shows that the NiTi-Nb eutectic alloy, with good mechanical properties in the as-cast structure without further themo-mechanical processing, can be cast using blends of $\mathrm{NiTi}$ and $\mathrm{Nb}$ powders, at temperatures which are much lower than needed when arc-melting pure $\mathrm{Ni}$, $\mathrm{Ti}$ and $\mathrm{Nb}$ feedstock.

\section{Summary}

A Ni-Ti-Nb alloy with the eutectic composition (nominally at Ti-40Ni-20Nb, at.\%) was cast into an ingot from prealloyed $\mathrm{NiTi}$ and $\mathrm{Nb}$ powders. $\mathrm{Nb}$ segregates to the bottom of the ingot, while $\mathrm{Ti}$ - and $\mathrm{Ni}$ - enrichment is present at the top of the ingot. In the ingot middle, a homogeneous $\mathrm{NiTi}-\mathrm{Nb}$ eutectic is found with an average composition of $\mathrm{Ti}-40.1 \mathrm{Ni}-19.6 \mathrm{Nb}$ at.\% . Equiaxed eutectic colonies, 50-100 $\mu \mathrm{m}$ in diameter, contain a fine lamellar eutectic microstructure with rod-shaped, Nb-rich lamellae, $\sim 0.5 \mu \mathrm{m}$ in diameter and $>30 \mu \mathrm{m}$ in length. An interphase with coarser eutectic microstructure and the same nominal composition exists between the eutectic colonies. The colonies consist of arrays of parallel lamellae with average $\mathrm{Nb}-19 \mathrm{Ti}-10 \mathrm{Ni}$ composition contained within a matrix with average Ti-41Ni-15Nb composition. Some $\mathrm{Ti}_{2} \mathrm{Ni}$ precipitates (with $\mathrm{Ti}-29 \mathrm{Ni}-16 \mathrm{Nb}$ composition) also exist in the interphase region.

Mechanical properties of the as-cast eutectic alloy were measured via hardness and compressive testing. The microhardness, $227 \pm 8 \mathrm{HV}$, is slightly lower than, but comparable to, 
literature values of $\mathrm{NiTi}-\mathrm{Nb}$ eutectic alloys textured by hot rolling. Under monotonic compression, the alloy shows a stiffness of $46 \mathrm{GPa}$, a yield strength of $630 \mathrm{MPa}$, and beyond yield, a near linear hardening behavior, reaching without failure a stress of $1080 \mathrm{MPa}$ at a strain of $14.7 \%$. Upon unloading, the alloy unloads first elastically ( $0.6 \%$ elastic strain recovery) and then superelastically (1.2\% superelastic strain recovery).

During load-unload deformation cycles performed to increasing compressive strain values, the superelastic recovery strain and residual plastic strain present at each unloading increase linearly with the total applied strain reached during the prior loading. For the relatively low strain range $(<10.5 \%)$ studied here, the NiTi matrix in the eutectic structure is expected to deform primarily by stress-induced transformation (i.e., superelastically) and to a less extent by dislocation-mediated plasticity, whereas the $\mathrm{Nb}$ lamellae are expected to exhibit elastic deformation followed by plastic deformation. Upon unloading, the $\mathrm{Nb}$ lamellae can only recover their elastic strain, while the NiTi matrix recovers both elastic and superelastic strain. The superelastic strain recovery is approximately double the total elastic strain recovery. This is highly promising for design of NiTi porous structures or composites using NiTi-Nb liquid sintering. The excellent mechanical properties, coupled with the superelastic properties, make it a good bonding material, while full characterization allows for use of the material in computational design.

\section{Acknowledgements}

This research was supported by the Office of Army Research (W911NF-12-10013/P00002), as well as the Department of Energy (DE-SC0010594). C. Bewerse also gratefully acknowledges Government support under, and awarded by, DoD, Air Force Office of 
Scientific Research, National Defense Science and Engineering Graduate (NDSEG) Fellowship, 32 CFR 168a.. This work made use of the EPIC facility (NUANCE Center-Northwestern University), which has received support from the MRSEC program (NSF DMR-1121262) at the Materials Research Center, and the Nanoscale Science and Engineering Center (EEC-

0118025/003), both programs of the National Science Foundation; the State of Illinois; and Northwestern University.

\section{References}

Akselsen, O. M. (2010). Joining of shape memory alloys. In Shape Memory Alloys (pp. 183210). Sciyo.

Arciniegas, M., Casals, J., Manero, J. M., Peña, J., \& Gil, F. J. (2008). Study of hardness and wear behaviour of NiTi shape memory alloys. Journal of Alloys and Compounds, 460(1-2), 213-219. doi:10.1016/j.jallcom.2007.05.069

Bansiddhi, A., \& Dunand, D. C. (2009). Shape-memory NiTi - Nb foams. Journal of Materials Research, 24(6), 2107-2117. doi:10.1557/JMR.2009.0256

Bansiddhi, A., \& Dunand, D. C. (2011a). Niobium Wires as Space Holder and Sintering Aid for Porous NiTi. Advanced Engineering Materials, 13(4), 301-305.

doi:10.1002/adem.201000241

Bansiddhi, A., \& Dunand, D. C. (2011b). Processing of NiTi Foams by Transient Liquid Phase Sintering. Journal of Materials Engineering and Performance, 20(4-5), 511-516. doi:10.1007/s11665-010-9827-6 
Bao, Z., Guo, S., Xiao, F., \& Zhao, X. (2011). Development of NiTiNb in-situ composite with high damping capacity and high yield strength. Progress in Natural Science: Materials International, 21(4), 293-300. doi:10.1016/S1002-0071(12)60060-4

Brinson, L. C., Schmidt, I., \& Lammering, R. (2003). Stress-Induced Transformation Behavior of a Polycrystalline NiTi Shape Memory Alloy: Micro and Macromechanical Investigations via in situ Optical Microscopy. Journal of the Mechanics and Physics of Solids.

Buxbaum, R. E., \& Marker, T. L. (1993). Hydrogen transport through non-porous membranes of palladium-coated niobium , tantalum and vanadium. Journal of Membrane Science, 85, 2938.

Chen, H., \& Du, Y. (2006). Refinement of the thermodynamic modeling of the Nb-Ni system. Calphad, 30(3), 308-315. doi:10.1016/j.calphad.2006.02.005

Choi, Y., Lee, B.-W., Lee, H.-S., \& Kwon, D. (2003). Indentation Curve Analysis for Pile-up, Sink-in and Tip-Blunting Effects in Sharp Indentations. MRS Proceedings, 795, U11.13. doi:Yeol Choi, Baik-Woo Lee, Ho-Seung Lee and Dongil Kwon (2003). Indentation Curve Analysis for Pile-up, Sink-in and Tip-Blunting Effects in Sharp Indentations. MRS Proceedings, 795, U11.13 doi:10.1557/PROC-795-U11.13.

Duwez, P., \& Taylor, J. L. (1950). The Structure of the Intermediate Phases in Alloys of Titanium with Iron, Cobalt and Nickel. Transactions of the American Institute of Mining and Metallurgical Engineers, 188, 1173-1176.

Emsley, J. (1999). The Elements (3rd ed.). Oxford, UK: Oxford Univesity Press. 
Grummon, D. S., Low, K.-B., Foltz, J., \& Shaw, J. A. (2007). A New Method for Brazing Nitinol Based on the Quasibinary TiNi-Nb System. In American Institute of Aeronautics and Astronautics (pp. 1-7).

Grummon, D., Shaw, J., \& Foltz, J. (2006). Fabrication of cellular shape memory alloy materials by reactive eutectic brazing using niobium. Materials Science and Engineering: A, 438-440, 1113-1118. doi:10.1016/j.msea.2006.03.113

Guanjun, Y., \& Shiming, H. (2000). Study on the phase equilibria of the Ti-Ni-Nb ternary system at 900C. Journal of Alloys and Compounds, 297, 226-230.

Hao, S., Cui, L., Chen, Z., Jiang, D., Shao, Y., Jiang, J., ... Ren, Y. (2013). A novel stretchable coaxial NiTi-sheath/Cu-core composite with high strength and high conductivity. Advanced Materials (Deerfield Beach, Fla.), 25(8), 1199-202. doi:10.1002/adma.201203762

Hashi, K., Ishikawa, K., Matsuda, T., \& Aoki, K. (2004). Hydrogen permeation characteristics of multi-phase Ni-Ti-Nb alloys. Journal of Alloys and Compounds, 368(1-2), 215-220. doi:10.1016/j.jallcom.2003.08.064

Humbeeck, J. Van. (1999). High Temperature Shape Memory Alloys. Transactions of the ASME, $121,98-101$.

Ishikawa, K., Seki, Y., Kita, K., Nishida, M., \& Aoki, K. (2011). Hydrogen permeability and microstructure of rapidly quenched $\mathrm{Nb}-\mathrm{TiNi}$ alloys. Journal of Alloys and Compounds, 509, S790-S793. doi:10.1016/j.jallcom.2010.10.126 
Ishikawa, K., Tokui, S., \& Aoki, K. (2009). Microstructure and hydrogen permeation of cold rolled and annealed Nb40Ti30Ni30 alloy. Intermetallics, 17(3), 109-114. doi:10.1016/j.intermet.2008.10.003

Jackson, C. M., Wagner, H. J., \& Wasilewski, R. J. (1972). 55-Nitinol-The Alloy with a Memory: Its Physical Metallurgy, Properties, and Applications (pp. 1-86). Washington, DC.

Kalidindi, S. R., Abusafieh, a., \& El-Danaf, E. (1997). Accurate characterization of machine compliance for simple compression testing. Experimental Mechanics, 37(2), 210-215. doi:10.1007/BF02317861

Kato, T., Ishikawa, K., \& Aoki, K. (2008). Effect of Ti/Ni Ratio and Annealing on Microstructure and Hydrogen Permeability of Nb-TiNi Alloy. Materials Transactions, 49(10), 2214-2219. doi:10.2320/matertrans.MA200851

Kishida, K., Yamaguchi, Y., Tanaka, K., Inui, H., Tokui, S., Ishikawa, K., \& Aoki, K. (2008). Microstructures and hydrogen permeability of directionally solidified $\mathrm{Nb}-\mathrm{Ni}-\mathrm{Ti}$ alloys with the Nb-NiTi eutectic microstructure. Intermetallics, 16(1), 88-95. doi:10.1016/j.intermet.2007.08.001

Krishnan, V. B., Bewerse, C., Notardonato, W. U., \& Vaidyanathan, R. (2008). A Thermal Conduction Switch based on Low Hysteresis NiTiFe Shape Memory Alloy Helical Springs. AIP Conference Proceedings, 986(1), 3-9. 
Liu, Y., Xie, Z., Van Humbeeck, J., \& Delaey, L. (1998). Asymmetry of stress-strain curves under tension and compression for NiTi shape memory alloys. Acta Materialia, 46(12), 4325-4338. doi:10.1016/S1359-6454(98)00112-8

Liu, Y. Z., Zhang, L. X., Liu, C. B., Yang, Z. W., Li, H. W., \& Feng, J. C. (2011). Brazing C/SiC composites and $\mathrm{Nb}$ with TiNiNb active filler metal. Science and Technology of Welding and Joining, 16(2), 193-198. doi:10.1179/1362171810Y.0000000021

Liu, Z., Cui, L., Liu, Y., Jiang, D., Jiang, J., Shi, X., ... Zheng, Y. (2014). Influence of internal stress coupling on the deformation behavior of NiTi-Nb nanowire composites. Scripta Materialia, 77, 75-78. doi:10.1016/j.scriptamat.2014.01.027

Liu, Z., Liu, Y., Jiang, D., Yang, F., Hao, S., Ren, Y., \& Cui, L. (2014). Local strain matching between $\mathrm{Nb}$ nanowires and a phase transforming NiTi matrix in an in-situ composite. Materials Science and Engineering: A. doi:10.1016/j.msea.2014.05.041

Matsuda, M., Shimada, Y., Murasaki, T., Nishida, M., Ishikawa, K., \& Aoki, K. (2009). Crystallization and microstructure changes in rapidly solidified Nb20Ti40Ni40 hydrogen permeation alloy. Journal of Alloys and Compounds, 485(1-2), 773-777. doi:10.1016/j.jallcom.2009.06.094

Matsumoto, S., Tokunaga, T., Ohtani, H., \& Hasebe, M. (2005). Thermodynamic Analysis of the Phase Equilibria of the Nb-Ni-Ti System. Materials Transactions, 46(12), 2920-2930.

Morgan, N. . (2004). Medical shape memory alloy applications—-the market and its products. Materials Science and Engineering: A, 378(1-2), 16-23. doi:10.1016/j.msea.2003.10.326 
Nemat-Nasser, S., \& Guo, W. (2000). Flow stress of commercially pure niobium over a broad range of temperatures and strain rates. Materials Science and Engineering: A, 284(1-2), 202-210. doi:10.1016/S0921-5093(00)00740-1

Neurohr, A. J., \& Dunand, D. C. (2011a). Mechanical anisotropy of shape-memory NiTi with two-dimensional networks of micro-channels. Acta Materialia, 59(11), 4616-4630. doi:10.1016/j.actamat.2011.04.007

Neurohr, A. J., \& Dunand, D. C. (2011b). Shape-memory NiTi with two-dimensional networks of micro-channels. Acta Biomaterialia, 7(4), 1862-72. doi:10.1016/j.actbio.2010.11.038

Okamoto, H. (2002). Nb-Ti (Niobium-Titanium). Journal of Phase Equilibria and Diffusion, 23, 553.

Otsuka, K., \& Ren, X. (1999). Recent developments in the research of shape memory alloys. Intermetallics, 7(5), 511-528. doi:10.1016/S0966-9795(98)00070-3

Piao, M., Miyazaki, S., Otsuka, K., \& Nishida, N. (1992). Effects of Nb Addition on the Microsctruture of Ti-Ni Alloys. Materials Transactions, JIM, 33(4), 337-345.

Prima, S. B., Tretyachenko, L., \& Petyukh, V. M. (1995). Phase Relations in the Ti-TiNi-NbNiNb Region of the Ternary System Ti-Nb-Ni. Powder Metallurgy and Metal Ceramics, 34(34), 155-160.

Song, G., Ma, N., \& Li, H.-N. (2006). Applications of shape memory alloys in civil structures. Engineering Structures, 28(9), 1266-1274. doi:10.1016/j.engstruct.2005.12.010 
Song, X. G., Cao, J., Liu, Y. Z., \& Feng, J. C. (2012). Brazing high Nb containing TiAl alloy using TiNi-Nb eutectic braze alloy. Intermetallics, 22, 136-141. doi:10.1016/j.intermet.2011.10.020

Vaidyanathan, R., Bourke, M. A. M., \& Dunand, D. C. (1999). Phase fraction, texture and strain evolution in superelastic NiTi and NiTi-TiC composites investigated by neutron diffraction. Acta Materialia, 47(12), 3353-3366.

Wu, M. H., \& Schetky, L. M. (2000). Industrial Applications for Shape Memory Alloys. In Proceedings of the International Conference on Shape Memory and Superelastic Technologies (Vol. 182, pp. 171-182). Pacific Grove, California, USA.

Xiao, F., Ma, G., Zhao, X., Xu, H., Jiang, H., \& Rong, L. (2007). A novel TiNiNb shape memory alloy with high yield strength and high damping capacity. SPIE Proceedings, 6423 , 64232L-64232L-6. doi:10.1117/12.779884

Yang, F., Devaraj, A., Noebe, R. D., Williams, R. E. A., Mills, M. J., Williams, D. B., \& Mccomb, D. W. (2013). Composition Analysis on the Precipitates in the NiTiHf and NiPdTiHf Alloys. Microscopy and Microanalysis, 19(Suppl 2), 1518-1519. doi:10.1017/S1431927613009586

Yin, X., Mi, X., Li, Y., \& Gao, B. (2012). Microstructure and Properties of Deformation Processed Polycrystalline Ni47Ti44Nb9 Shape Memory Alloy. Journal of Materials Engineering and Performance, 21(December), 2684-2690. doi:10.1007/s11665-012-0376-Z 
Ying, C., Hai-chang, J., Li-jian, R., Li, X., \& Xin-qing, Z. (2011). Mechanical behavior in NiTiNb shape memory alloys with low Nb content. Intermetallics, 19(2), 217-220. doi:10.1016/j.intermet.2010.08.011

\section{Figure Captions}

